\title{
Predicting Mathematical Learning Difficulties Status: The Role of Domain-Specific and Domain-General Skills
}

\author{
Riikka Mononen $^{\text {1 }}$, Markku Niemivirta ${ }^{\text {b, }}$, and Johan Korhonen ${ }^{d}$ \\ ${ }^{a}$ Department of Special Needs Education, University of Oslo, Norway \\ ${ }^{\mathrm{b}}$ School of Applied Educational Science and Teacher Education, \\ University of Eastern Finland, Finland \\ ${ }^{c}$ Department of Education, University of Helsinki, Finland \\ ${ }^{d}$ Faculty of Education and Welfare Studies, Åbo Akademi University, Vaasa, Finland
}

\begin{abstract}
This study investigated which domain-specific and domain-general skills measured at grade 1 predict mathematical learning difficulties (MLD) status at grade 3 . We used different cut-off criteria and measures of mathematics performance for defining the MLD status. Norwegian children's $(N=206)$ numeracy, cognitive, and language skills were measured at grade 1 and arithmetic fluency and curriculum-based mathematics (CBM) at grade 3. Logistic regression analyses showed that symbolic numerical magnitude processing, verbal counting, and rapid automatized naming predicted MLD25 status (performance $\leq 25$ th percentile) based on arithmetic fluency, whereas verbal counting skills and nonverbal reasoning predicted the status based on CBM. The same predictors were found for MLD10 status (performance $\leq 10$ th percentile), and in addition, rapid automatized naming also predicted the status based on CBM. Only symbolic numerical magnitude processing and verbal counting predicted LOW status (performance between 11-25th percentile) based on arithmetic fluency, whereas nonverbal reasoning and working memory predicted LOW status based on CBM. Different cut-off scores and mathematics measures used for the definition of MLD status are important to acknowledge, as these seem to lead to relatively significant variation in which students are identified as having MLD and which factors contribute to the MLD status.
\end{abstract}

Keywords: arithmetic, counting, mathematical learning difficulties, nonverbal reasoning, rapid automatized naming

Corresponding concerning this article should be addressed to Riikka Mononen, Department of Special Needs Education, P.O. Box 1140, Blindern, 0318 Oslo, Norway. Email: r.m.mononen@isp.uio.no

Preprint version 3, accepted for publication 5 December 2021

\footnotetext{
${ }^{1}$ corresponding author
} 


\section{Introduction}

Individual differences in mathematics learning and performance in the beginning of schooling are well-acknowledged (Aunio \& Niemivirta, 2010; Jordan et al., 2009; ten Braak et al., 2022; Zhang et al., 2020). Children in early grades are rarely formally diagnosed as having developmental learning disorder in mathematics, also called dyscalculia, until the effect of teaching has been taken into account (ICD-11; World Health Organization, 2019). Nonetheless, we can reliably identify students who perform weaker in mathematics than their peers and show difficulties in their mathematics learning. In research literature, different cut-off criteria for performance, ranging from 10th to 35th percentile, have been used to identify students at risk for or having mathematical learning difficulties (MLD) (e.g., Aunio et al., 2021; Kroesbergen \& van Dijk, 2015; Lin et al., 2021; Mazzocco et al., 2013). A wide cut-off range used for the definition of MLD leads to an inclusion of a variety of performance within MLD; the lower end showing more severe difficulties than the upper end. Not until recently have the researchers started to show more consensus on the terms and cut-off criteria of MLD. Individuals performing at the lowest 10th percentile are commonly referred to as having mathematical disability/disorder or developmental dyscalculia, whereas those performing between the 11th and 25th percentile are referred to as lowperforming/achieving (Geary, 2011). The term mathematical learning difficulties, independent of the severity of MLD, can then be used as an umbrella term for all those performing at or below the 25th percentile.

In addition to the severity criteria, different types of mathematics measures are used in research to identify students with MLD. Measures of arithmetic performance are typically applied (Cañizares et al., 2012; Koponen, Aro, et al., 2018), as poor arithmetic fluency is one of the main characteristics of students having MLD (Geary, 2011; Gersten et al., 2005). Alternatively, broad mathematics performance measures are used (Jordan et al., 2002). Sometimes the definition of MLD includes a persistence criterion, meaning that the student needs to perform low in at least two consecutive time points (Mazzocco et al., 2013; Stock et al., 2010). Currently, we have little knowledge of the extent to which the different mathematics measures overlap in defining MLD. That is, would a brief arithmetic fluency measure identify the same students as a broader mathematics performance test?

Researchers have also been curious about which domain-specific and domaingeneral skills are related to or may contribute to MLD, and whether these differ between the subgroups of MLD (Geary et al., 2012; Huijsmans et al., 2022; Salihu \& Räsänen, 2018). A set of domain-specific skills, such as numerical magnitude processing (Cañizares et al., 2012; De Smedt \& Gilmore, 2011) and counting skills (Koponen et al., 2019), and domain-general skills, such as working memory (Menon, 2016; Passolunghi \& Mammarella, 2010) and rapid automatized naming (Van Luit \& Toll, 2018), have been found to be related to MLD. However, drawing conclusions about their predictive role becomes complicated due to the different cut-off criteria for MLD and various measures used for the identification of students with MLD.

On one hand, it has been suggested that deficit in either numerical magnitude processing (NMP) (Butterworth, 2005) or accessing the magnitude in symbols (Rousselle \& Noël, 2007) underlies the most severe MLD (but see Mammarella et al., 2021 for no evidence for a core deficit in MLD). On the other hand, a persistent low performance in mathematics has been suggested to stem from having weaknesses in domain-general cognitive skills (e.g., working memory) or lacking mathematics 
motivation (Geary, 2011; Price \& Ansari, 2013). By contrast, the double deficit model suggests that weaknesses in both NMP and working memory would be associated with the most severe MLD (Kroesbergen \& van Dijk, 2015). While there are competing theories about the associations between domain-specific and domain-general skills and MLD, and whether these differ between the subtypes of MLD (Geary et al., 2012; Huijsmans et al., 2022; Tolar et al., 2016), the empirical evidence has mostly relied on cross-sectional data, thus focusing only on the concurrent relations between the predictors and MLD status (e.g., Cañizares et al., 2012; Passolunghi \& Mammarella, 2010; Tolar et al., 2016; Van Luit \& Toll, 2018; Willburger et al., 2008). Longitudinal data would seem more accurate in identifying the most relevant domain-specific and domain-general predictors of MLD status.

Our study adds to the current research by investigating which domain-specific and domain-general skills measured in the first grade predict MLD status in the third grade. The novelty of our study lies in taking into consideration different cut-off criteria and mathematics measures (i.e., arithmetic fluency and curriculum-based mathematics $[\mathrm{CBM}]$ ) in defining the MLD. Further, we include simultaneously several domainspecific (i.e., symbolic numerical magnitude processing [SNMP] and counting skills) and domain-general skills (i.e., nonverbal reasoning, working memory, rapid automatized naming, and vocabulary) as predictors of MLD status. To examine if domain-specific and domain-general skills predict MLD status differently when using different cut-off criteria based on the sample-based percentiles, we first divide the students into two groups: those who perform at or below the 25th percentile are referred to as having mathematical learning difficulties (MLD25), while rest of the students are referred to as typically performing (performance over the 25 th percentile). Next, we divide the MLD25 group into those who are showing more severe difficulties, namely mathematical learning disorder (performance at or below the 10th percentile, MLD10) and those who are low performing (performance between the 11th to 25th percentile, LOW). The status of MLD is based separately on arithmetic fluency and on CBM. This enables us to examine the overlap of MLD statuses based on arithmetic fluency and CBM (e.g., how many students are classified as MLD25 in both arithmetic fluency and CBM), and whether predictors of MLD status vary as a function of mathematics measure (arithmetic fluency vs. CBM) and cut-off criteria (10th vs. 25th percentile).

\section{Domain-Specific Skills as Predictors of MLD}

Domain-specific skills in mathematics context mean different mathematical skills. Here, we focus on two such skills, numerical magnitude processing (NMP) and counting skills, which have shown to be related to or to predict later mathematics performance, concerning both the typically performing students and students with MLD. NMP is considered to be an innate ability, which enables individuals to approximately process numerical magnitudes (Dehaene et al., 1998). A traditionally used task for measuring NMP is to compare two sets of dots, and to quickly decide which side has more dots. Even if some studies have shown that students with MLD often have poorer NMP skills compared to their peers without MLD (Mazzocco et al., 2011; Mussolin et al., 2010), there is recent evidence showing that symbolic NMP (SNMP) would be even a better predictor of mathematics performance and more strongly associated with MLD than non-symbolic NMP (Cañizares et al., 2012; De Smedt \& Gilmore, 2011; Desoete et al., 2012; Nosworthy et al., 2013). For this reason, we focus in this study on the role of SNMP. The tasks often used to measure SNMP are similar to NMP comparison tasks, but 1- or 2-digit numbers are used as stimuli instead 
of dots (Brankaer et al., 2017). While comparing the numbers, and to choose the bigger number, the student needs to access the magnitudes of those numbers. A slow response indicates a deficit in accessing and processing of the magnitudes (Rousselle \& Noël, 2007). Concerning school beginners, Desoete et al. (2012) found that SNMP measured in kindergarten (5-6 years old) was a good predictor of procedural calculations (i.e., 34 +21 , or given in as " 6 more than 48 is...") in the second grade. Further, they found that although children with MLD showed weakness in both non-symbolic and symbolic NMP in kindergarten, it was only in SNMP they showed a deficit in grade 2. Overall, the findings are still mixed when it comes to the role of (S)NMP and severity level of MLD. Some research supports that students with severe MLD are characterized with poor NMP (Mazzocco et al., 2011), while some research has not found a difference between the subgroups of MLD (i.e., MLD10 and LOW) (Huijsmans et al., 2022)

Counting skills (i.e., verbal number sequence skills and object counting) develop typically parallel with early arithmetic skills (i.e.., addition and subtraction), and can also be seen as prerequisites for learning arithmetic skills, because children often use these as their strategies in solving arithmetic calculation problems (Koponen et al., 2019). Typically, children with MLD use more immature, counting-based strategies, while their peers use retrieval strategies, that is, they quickly retrieve the answer from long-term memory (Ostad, 1998). Counting skills have been found to be associated with (Lopez-Pedersen et al., 2021) and to predict later arithmetic and mathematics performance (Aunio \& Niemivirta, 2010; Koponen et al., 2019). Furthermore, children performing low (Hassinger-Das et al., 2014; Toll \& Van Luit, 2014) and with severe MLD (Landerl et al., 2004) have shown weaker counting skills compared to their peers.

\section{Domain-General Skills as Predictors of MLD}

Several domain-general skills, such as working memory, executive functions, rapid automatized naming, and language, have been found to be associated with mathematics performance and development (Chu et al., 2016; Friso-van den Bos et al., 2013; Koponen, Eklund, et al., 2018; Purpura \& Ganley, 2014), and with MLD (Mammarella et al., 2021; Passolunghi \& Mammarella, 2010; Purpura et al., 2017; Van Luit \& Toll, 2018). Further, separate domain-general cognitive profiles depending on the severity level of MLD has been suggested (Geary et al., 2012). However, in a recent study, Hujsman et al. (2022) did not find support for this. In their study, the severity of MLD did not result in differences in the cognitive profiles, and further, the cognitive profiles for mathematics development from fourth to fifth grade were rather similar between the students with MLD and typically performing students.

Nonverbal reasoning (also called as nonverbal or fluid intelligence) has been shown to be a consistent predictor of mathematics performance in different age groups of students (Kyttälä \& Lehto, 2008; Pina et al., 2014). Good nonverbal reasoning skills are an advantage in solving mathematical problems, because students need to be able to make logical decisions and to proceed systematically with the task (e.g., entertain their solutions and if proven false try a new solution) (Engle, 2018). Students with MLD typically perform weaker in nonverbal reasoning, albeit within normal range, compared to their peers without MLD (Huijsmans et al., 2022).

Solving mathematics tasks requires working memory capacity for storing and manipulating information temporarily. Working memory and its different components (i.e., visuo-spatial sketchpad, phonological loop, central executive) have all been linked with mathematics performance (Friso-van den Bos et al., 2013). Students with MLD have been reported to show weaker working memory performance than their peers 
(Kroesbergen \& van Dijk, 2015; Passolunghi \& Mammarella, 2010). Huijsmans et al. (2022) found that those with low performance were characterized by difficulties in visual working memory, but interestingly, not those with severe MLD. However, working memory did not explain any variance in the mathematics development from fourth to fifth grade (Huijsmans et al., 2022). Our study, instead, focuses on the central executive component of working memory (i.e., manipulation of information). Prior research has shown that students with MLD have a deficit in their central executive functioning, and especially when central executive has been measured with numerical stimuli (Andersson \& Lyxell, 2007; for a meta-analysis see David, 2012).

Rapid automatized naming (i.e., quickly naming familiar non-alphanumeric objects such as colors and figures, or alphanumeric objects such as letters or numbers) has been found to be more strongly related to arithmetic fact retrieval than to more general mathematics performance (for a meta-analysis see Koponen et al., 2017). Rapid automatized naming (e.g., naming a color) and fact retrieval (e.g., $5+3$ ) both require quick access to and retrieval of phonological representations from long-term memory ("blue" and "eight", respectively) (Koponen et al., 2017). Concerning students with MLD, Donker et al. (2016) found that primary school-aged students had weaker performance in non-alphanumeric rapid automatized naming (e.g., colors) compared to their peers, but not in alphanumeric format (e.g., letters). Further, Mazzocco and Grimm (2013) found in their longitudinal study from kindergarten to grade 8 that those with LOW showed slight delays (i.e., slower response times) in naming of colors compared to their TYP peers, whereas those with severe MLD showed more persistent weakness in rapid naming of letters and colors. Based on prior findings that rapid naming of colors can be a good early predictor of mathematics performance and especially arithmetic fact retrieval (Koponen et al., 2017), and associated with MLD (Donker et al., 2016; Mazzocco \& Grimm, 2013), in our study, we chose to have rapid naming of colors as a proxy for rapid automatized naming.

In early childhood, language skills have been linked with mathematics performance (Aunio et al., 2019), and especially mathematics related language to be a good predictor of low performance (Purpura et al., 2017), as well as influencing the development of early mathematical skills of LOW (Toll \& Van Luit, 2014). In our study, we focus on vocabulary (expressive) in general, which has shown to play a role in children's mathematics learning (LeFevre et al., 2010). However, also conflicting results have been reported among school beginners, that is, no connection between vocabulary (receptive) and mathematics performance (Chow \& Ekholm, 2019). Vocabulary is needed not only to understand mathematics teaching in general, but also to communicate using different mathematics concepts (e.g., comparison words, number words, geometrical object, words for operations [e.g., plus, minus]. Support for the importance of language in mathematics learning comes from studies, which have included students with developmental language disorder. In general, these students have consistently shown weaker mathematics performance compared to their peers in mathematical tasks that require expressing or understanding of language (e.g., verbal number sequences, counting of objects, arithmetic) while they have shown similar performance to their TYP peers in mathematics tasks with less demand on language (e.g., NMP, conceptual mathematics tasks) (for a review see Cross et al., 2019). Not many studies have investigated the role of different components of language among students with MLD. However, recently, Chow et al. (2021) showed that students with 
MLD (performance below 20th percentile on arithmetic fluency) performed lower than their peers in receptive vocabulary, morphology, and syntax.

\section{Present Study}

The present study expands on previous research by investigating how domainspecific and domain-general skills measured in the first grade predict MLD status among third graders when different cut-off criteria and measures of mathematics performance are used. Our research questions are as follows:

(RQ1) What is the overlap of MLD statuses based on arithmetic fluency and curriculum-based mathematics?

(RQ2) How do domain-specific (i.e., symbolic numerical magnitude processing and verbal counting skills) and domain-general (non-verbal reasoning, rapid automatized naming, working memory, and vocabulary) skills predict MLD status when using the 25th percentile cut-off criterion (MLD25) based on either arithmetic fluency (RQ2.1) or curriculum-based mathematics (RQ2.2)?

(RQ3) How do domain-specific and domain-general skills predict MLD status when further dividing the MLD25 into MLD10 ( $\leq 10$ th percentile) and low performers (LOW; 11-25th percentile) based on either arithmetic fluency (RQ3.1) or curriculumbased mathematics (RQ3.2)?

Although we have limited evidence available to strongly guide our hypothesis for RQ1, we expect relatively high overlap of MLD statuses based on different mathematics measures, but still distinct to a certain degree, as the mathematics content in arithmetic fluency is much more limited than in the broad CBM measure (H1).

Based on prior research, we hypothesize that all domain-specific and domaingeneral skills under investigation are likely predictors of MLD25 (H2), as this group encompasses those with more severe learning difficulties (MLD10) and milder learning difficulties (LOW). Regarding MLD25 based on arithmetic fluency, we expect SNMP (Desoete et al., 2012), counting skills (Hassinger-Das et al., 2014; Landerl et al., 2004) and rapid automatized naming (Koponen et al., 2017; Mazzocco \& Grimm, 2013) to be significant predictors $(\mathrm{H} 2.1)$. Since the tasks in CBM have more variety and complexity regarding their mathematics content and procedures, thus requiring logical reasoning (Engle, 2018), executive functioning (David, 2012), and understanding task related vocabulary (Chow et al., 2021), we anticipate MLD25 based on CBM to be predicted by counting skills (Hassinger-Das et al., 2014), nonverbal reasoning, working memory, and vocabulary (H2.2).

Similar to MLD25 based on arithmetic fluency, we expect the two domain-specific skills and rapid automatized naming to predict both MLD10 and LOW status (H3.1). As to the status based on CBM, we presume domain-general skills, especially concerning working memory (David, 2012; Huijsmans et al., 2022), to exhibit different predictions on MLD10 and LOW (David, 2012; Huijsmans et al., 2022). Further, we expect the significant predictors to include counting skills (Hassinger-Das et al., 2014; Landerl et al., 2004), nonverbal reasoning (Huijsmans et al., 2022), and vocabulary (Chow et al., 2021) (H3.2).

\section{Method}

\section{Participants}

The current study is part of a research project that follows Norwegian children's numeracy development from first to third grade. Here, we use data from its first (grade $1, \mathrm{t} 1)$ and last (grade 3, t2) measurement time points. The final sample of participants 
was 206 children (Mage $=6$ y. 9 m., $S D=3.4$ m., girls 49\%), from four schools located in the Oslo region, and who had data available from both time points. Due to Covid-19 restrictions in schools in spring 2021, 27 children from the initial sample of 265 were not able to participate in $\mathrm{t} 2$, and 32 children had either moved away or were absent from school on the data collection day. An ethical approval was given by the Norwegian Centre for Research Data before the data collection started, and consents for the participation were given by children's legal guardians.

\section{Measures}

\section{Third-Grade Mathematics Performance}

Arithmetic fluency was measured using a standardized arithmetic test Regnefaktaprøven (Klausen \& Reikerås, 2016). Children have 2 minutes to solve as many addition problems as possible out of 45 on one sheet, and same for subtraction. As a proxy of arithmetic fluency, we combined the sum scores of each subtest, thus the maximum possible score being 90 points.

A curriculum-based mathematics (CBM) test was developed in the project (author, 2021) to measure children's overall performance in mathematics taught in grade 3 . This paper-pencil group-based test includes 49 items from the topics of numbers (number sequences, comparison of multi-digit numbers), measurement (volume, length, money), calculations (multiplication facts, addition and subtraction algorithms) and fractions, and follows the learning outcomes set for the third grade in the national mathematics curriculum (ref.). Each task was instructed for the children and children worked with the tasks independently for 20-25 minutes. Each correctly solved item gave one point.

\section{First-Grade Domain-Specific Numeracy Skills}

Symbolic numerical magnitude processing was measured using the 1-digit subtest of the SYMP test (Brankaer et al., 2017). In this paper-pencil test the child has 30 seconds to compare as many 1-digit number pairs as possible out of 60 , by choosing the bigger number. One point is given for a correct answer, thus the maximum score being 60 .

Verbal counting skills were measured using a normed Finnish LukiMat subscale (Salminen \& Koponen, 2011), which was translated into Norwegian. The child was asked to orally count number sequences forwards and backwards, in steps of 1, 2, 5, and 10. Each correctly given number sequence gave one point, the possible maximum total score being 29 points.

\section{First-Grade Domain-General Skills}

Nonverbal reasoning skills were measured using Raven's progressive colored matrices (Raven et al., 1990). The child chooses one of the six alternative pieces that fits the picture. One point was given for each correct answer, the maximum possible score being 34 , as two first items were practice items.

Working memory was measured using a digit span backwards subtest from WISCV (Wechsler, 2017). Digit span backwards captures the central executive component of WM, as modelled by Baddeley (Baddeley \& Logie, 1999). Each digit span, ranging from 2-8 numbers, had two tasks, except for 2- and 3-digit spans having 4 tasks each. Each digit span was presented orally to the child forwards and the child needed to repeat the digits backwards. Following the test guidelines, the test was stopped if the child could not give a correct answer for both tasks with the same number of digits. The maximum total score was 18 points. 
Rapid automatised naming was measured using a colors subtest from the Clinical Evaluation of Language Fundamentals (CELF-4) (Semel et al., 2003). The child needs to name 36 colored dots (including colors "gul" [yellow], "grønn" [green], "blå" [blue], "rød" [red]) as accurately and fast as possible. For the purpose of statistical analyses, we created a composite score, in which the correct number of named colors was divided by used time, and multiplied by ten.

Vocabulary was measured using a subtest 'Ordforstålse' of WISC-V (Wechsler, 2017) targeting expressive vocabulary. A child needs to either name a picture (first 4 items, 1 point for a correct answer), or explain the meaning of a word ( 25 items, giving either 1 or 2 points depending on the correctness of the definition based on the test guidelines). A maximum score for the task was 54 points.

\section{Procedure}

The first data collection (t1) took place in spring 2019. Children came in groups of $8-10$ students to the data collection site for half a school day. During this "adventure day" the children completed a set of measures individually and in small groups depending on the test format, together with trained research assistants. Small breaks were held between the sessions. The data collection in the third grade ( $\mathrm{t} 2$ ) took place in spring 2021. The Covid-19 measures set by the Norwegian government restricted the data collection so that we were not allowed to visit the schools. Instead, one research assistant gave all test instructions online via Teams to one classroom at a time, and the students in the classroom were overlooked by their classroom teacher. The testing was done in two sessions of around 45 minutes each, during one day. The research assistants had a video and audio connections to the classroom. No such technical issues were reported that would have violated the testing situation and validity of the data. Test booklets were delivered to the schools a few days before the data collection took place and collected after the data collection was completed.

The data was coded by trained research assistants, and data from three randomly chosen students per classroom (13\%) were double coded by the first author. The correlations between the first and second coding resulted in correlations of sum scores ranging from $r=.944-1.00$, with coding errors connected to some children having few items in a test with non-matching values. When needed, the test papers compared to the punched values, and the final data matrix corrected accordingly.

\section{Data analysis}

First, descriptive statistics of and correlations between all variables were calculated. Second, grouping variables for the MLD status based on sample-based percentiles both in third grade arithmetic fluency and CBM were created. The first grouping variable for arithmetic fluency included MLD25 status and those performing typically (TYP). The second grouping variable for arithmetic fluency included MLD10, LOW and TYP. Similar grouping variables were created for CBM. To answer for RQ1, we tested with a chi-square test what is the overlap of MLD statuses based on arithmetic fluency and curriculum-based mathematics (e.g., children having a status of LOW in both arithmetic fluency and CBM). To answer for RQ2 and RQ3, which first-grade domain-specific and domain-general skills predict MLD status, we conducted two binary logistic regression analyses, one for arithmetic fluency and one for CBM, when having two status groups (MLD25 and TYP), and two multinomial logistic regression analyses when having three status groups (MLD10, LOW and TYP). Jamovi 2.2.2.0 software (The jamovi project, 2021) was used for statistical data analyses. 


\section{Results}

Descriptive statistics of and correlations between the variables are reported in Table 1. SNMP showed a stronger relation with arithmetic fluency $(r=.52)$ than with CBM $(r$ $=.30)$, whereas counting skills had a moderate relation with both $(r=.55$ and $r=.49$, respectively). The associations between domain-general skills and arithmetic fluency were weak with correlations ranging from $r=.23$ to $r=.43$, rapid automatized naming showing the strongest relation, and vocabulary the weakest. Regarding the relations with CBM, the strongest association was with nonverbal reasoning, $r=.43$, and weakest with rapid automatized naming, $r=.21$. Multicollinearity was unlikely as all correlations between the predictors were moderate at best.

Table 1

Descriptive Statistics of and Correlations between the Variables

\begin{tabular}{|c|c|c|c|c|c|c|c|c|}
\hline & 1. & 2. & 3. & 4. & 5. & 6. & 7. & 8. \\
\hline 1. SNMP $\mathrm{t} 1$ & - & & & & & & & \\
\hline 2. Counting t 1 & $0.46^{* * *}$ & - & & & & & & \\
\hline 3. Nonverbal reasoning $\mathrm{t} 1$ & $0.25 * * *$ & $0.28 * * *$ & - & & & & & \\
\hline 4. Working memory $\mathrm{t} 1$ & $0.25 * * *$ & $0.41^{* * *}$ & $0.31 * * *$ & - & & & & \\
\hline 5. Rapid naming $t 1$ & $0.42^{* * *}$ & $0.29 * * *$ & $0.23^{* *}$ & $0.33^{* * *}$ & - & & & \\
\hline 6. Vocabulary $\mathrm{t} 1$ & 0.13 & $0.28^{* * *}$ & $0.21 * *$ & $0.21 * *$ & 0.13 & - & & \\
\hline 7. Arithmetic fluency $\mathrm{t} 2$ & $0.52^{* * *}$ & $0.55^{* * *}$ & $0.28^{* * *}$ & $0.39^{* * *}$ & $0.43^{* * *}$ & $0.23 * * *$ & - & \\
\hline 8. CBM 2 & $0.30^{* * *}$ & $0.49 * * *$ & $0.43 * * *$ & $0.34 * * *$ & $0.33 * * *$ & $0.21 * *$ & $0.61^{* * *}$ & - \\
\hline$M$ & 17.39 & 20.22 & 24.18 & 6.26 & 10.00 & 13.45 & 36.58 & 34.76 \\
\hline$S D$ & 4.13 & 5.80 & 5.16 & 1.74 & 2.47 & 3.23 & 16.90 & 9.22 \\
\hline Min-Max & $7-29$ & $0-29$ & $8-34$ & $0-11$ & $2.09-18.95$ & $2-24$ & $2-89$ & $5-48$ \\
\hline Skewness & 0.06 & -0.89 & -0.32 & -0.03 & 0.08 & -0.02 & 0.52 & -1.05 \\
\hline Kurtosis & -0.06 & 0.51 & -0.39 & 0.53 & 1.32 & 1.09 & 0.33 & 0.89 \\
\hline Cronbach's $\alpha$ & .887 & .914 & .934 & .692 & .983 & .747 & .971 & .918 \\
\hline
\end{tabular}

Means and standard deviations on arithmetic fluency and CBM by each status group are reported in Table 2. As to RQ1, the chi-square test of the crosstabulation of MLD25 and TYP based on arithmetic fluency and CBM was significant, $\chi^{2}(1)=59.40$, $p<.001$. Sixty-five percent of children were observed as MLD25 in both arithmetic fluency and CBM, while $88 \%$ of children as TYP. Similarly, the crosstabulation of three groups, MLD10, LOW, and TYP, based on arithmetic fluency and CBM turned out to be significant, $\chi^{2}(4)=104.01, p<.001$. Sixty-seven percent of the children were observed as MLD10 in both arithmetic fluency and CBM, whereas only $39 \%$ of LOW, and $88 \%$ of TYP. These results confirmed that a series of separate logistic regression analyses for arithmetic fluency and CBM would be justified. 
Table 2

Means and Standard Deviations for Arithmetic Fluency and Curriculum-Based Mathematics (CBM) by Each Status Group

\begin{tabular}{|c|c|c|c|c|}
\hline & TYP & MLD25 & LOW & MLD10 \\
\hline & $\begin{array}{c}M \\
(S D) \\
n\end{array}$ & $\begin{array}{c}M \\
(S D) \\
n\end{array}$ & $\begin{array}{c}M \\
(S D) \\
n\end{array}$ & $\begin{array}{c}M \\
(S D) \\
n\end{array}$ \\
\hline $\begin{array}{l}\text { Arithmetic fluency t } 2 \text { a } \\
(\max .90 \text { p.) }\end{array}$ & $\begin{array}{c}43.29 \\
(13.78) \\
154\end{array}$ & $\begin{array}{c}16.69 \\
(6.28) \\
52\end{array}$ & $\begin{array}{c}21.16 \\
(2.05) \\
31\end{array}$ & $\begin{array}{c}10.10 \\
(4.21) \\
21\end{array}$ \\
\hline $\begin{array}{l}\text { CBM t } 2^{\mathrm{b}} \\
(\max .49 \mathrm{p} .)\end{array}$ & $\begin{array}{c}39.14 \\
(4.68) \\
154\end{array}$ & $\begin{array}{l}21.81 \\
(6.85) \\
52\end{array}$ & $\begin{array}{c}26.60 \\
(1.65) \\
30\end{array}$ & $\begin{array}{c}15.27 \\
(5.72) \\
22\end{array}$ \\
\hline
\end{tabular}

Note. TYP $=$ typically performing (performance $>25$ th percentile), MLD25 $=$ mathematical learning difficulties (performance $\leq 25$ th percentile), LOW $=$ low-performing (performance between 11-25th percentile), MLD10 = mathematical learning disorder (performance $\leq 10$ th percentile). ${ }^{\text {a }}$ The participants in each group are based on their performance on Arithmetic fluency. ${ }^{\mathrm{b}}$ The participants in each group are based on their performance on CBM. The LOW and MLD10 include the same participants as the MLD25.

\section{Predictors of MLD25 Status}

Arithmetic Fluency (RQ2.1)

A binary logistic regression analysis was performed to ascertain the effects of domain-specific skills (i.e., SNMP and counting skills) and domain-general skills (i.e., nonverbal reasoning, working memory, rapid automatized naming, and vocabulary) on the likelihood that participants have MLD25 status. The logistic regression model was statistically significant, $\chi^{2}(6)=61.69, p<.001$, and explained $42.0 \%$ (Nagelkerke $R^{2}$ ) of the variance in MLD status (Table 3 ). The model correctly classified $83.0 \%$ of cases. With a cutoff set at 0.5 , the prediction for children with TYP status was more accurate (94.9\%) than those with MLD25 (50.0\%). Two domain-specific and one domaingeneral skill predicted the MLD25 status: $\operatorname{SNMP}(B=-.18, p=.005$, odds ratio $=.83)$, counting skills $(B=-.14, p=.001$, odds ratio $=.87)$, and rapid automatized naming $(B=$ $-.22, p=.035$, odds ratio $=.80)$. Decreasing performance in these three skills was associated with increasing likelihood of MLD25 status. These are illustrated in Figure 1.

Table 3

Logistic Regression Analysis for MLD25 Status on Arithmetic Fluency

\begin{tabular}{lccccccc}
\hline & & & & & & \multicolumn{2}{c}{$95 \%$ CI for OR } \\
\cline { 6 - 8 } Predictor & $B$ & $S E$ & $Z$ & $p$ & OR & Lower & Upper \\
\hline Intercept & 6.69 & 1.64 & 4.07 & $<.001$ & NA & NA & NA \\
SNMP t1 & -0.18 & 0.06 & -2.84 & $\mathbf{0 . 0 0 5}$ & 0.83 & 0.73 & 0.94 \\
Counting t1 & -0.14 & 0.04 & -3.20 & $\mathbf{0 . 0 0 1}$ & 0.87 & 0.80 & 0.95 \\
Nonverbal reasoning t1 & 0.02 & 0.04 & 0.46 & 0.643 & 1.02 & 0.94 & 1.11 \\
Working memory t1 & -0.11 & 0.13 & -0.83 & 0.408 & 0.90 & 0.69 & 1.16 \\
Rapid naming t1 & -0.22 & 0.10 & -2.11 & $\mathbf{0 . 0 3 5}$ & 0.80 & 0.66 & 0.98 \\
Vocabulary t1 & 0.02 & 0.07 & 0.30 & 0.767 & 1.02 & 0.89 & 1.17 \\
\hline Model fit measures & Deviance & AIC & $R^{2} \mathrm{~N}$ & $\chi^{2}$ & df & $p$ & \\
\hline & 149.54 & 163.54 & 0.42 & 61.68 & 6 & $<.001$ & \\
\hline
\end{tabular}

Note. Estimates represent the log odds of MLD25 vs. TYP (reference group). MLD25 = mathematical learning difficulties (performance $\leq 25$ th percentile), TYP $=$ typically performing (performance $>25$ th percentile). $\mathrm{SNMP}=$ symbolic numerical magnitude processing, $\mathrm{OR}=$ odds ratio, $\mathrm{CI}=$ confidence interval, AIC = Akaike information criterion, $R^{2} \mathrm{~N}=$ Nagelkerke's $R^{2}$. 
a)

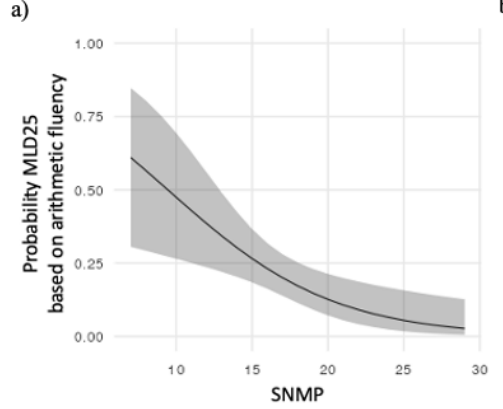

b)

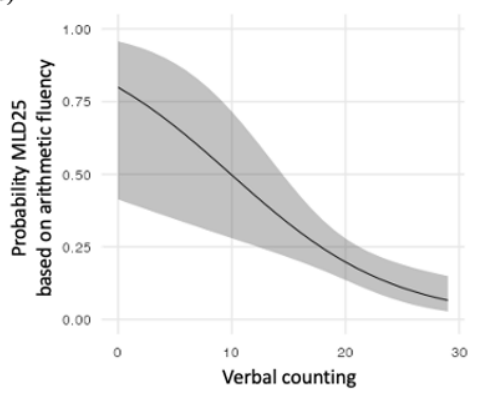

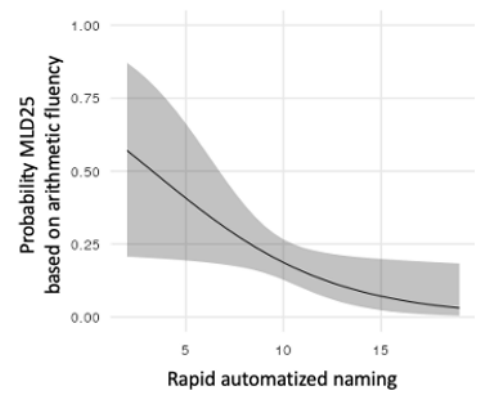

Figure 1

Predicted Probability with 95\% Confidence Interval for a Status of MLD25 in Arithmetic Fluency versus a) Symbolic Numerical Magnitude Processing (SNMP), b) Verbal Counting, and c) Rapid Automatized Naming

\section{Curriculum-Based Mathematics (RQ2.2)}

A similar binary logistic regression analysis was conducted for CBM as for arithmetic fluency. The logistic regression model showed to be statistically significant, $\chi^{2}(6)=34.89, p<.001$, and explained $26.0 \%$ of the variance in MLD25 status (Table 4 ). The model correctly classified $79.0 \%$ of cases. With a cutoff set at 0.5 , the prediction for children with TYP status was more accurate (94.2\%) than those with MLD25 (34.8\%). One domain-specific and one domain-general skill predicted the MLD25 status: counting skills $(B=-.09, p=.026$, odds ratio $=.92)$ and nonverbal reasoning $(B$ $=-.12, p=.003$, odds ratio $=.89$ ). Decreasing performance in these two skills was associated with a higher probability of MLD25 status, as illustrated in Figure 2.

Table 4

Logistic Regression Analysis for MLD25 Status on Curriculum-Based Mathematics

\begin{tabular}{lccccccc}
\hline & & & & & & \multicolumn{2}{c}{$95 \%$ CI for OR } \\
\cline { 6 - 8 } Predictor & $B$ & $S E$ & $Z$ & $p$ & OR & Lower & Upper \\
\hline Intercept & 4.67 & 1.31 & 3.57 & $<.001$ & NA & NA & NA \\
SNMP t1 & 0.02 & 0.06 & 0.36 & 0.715 & 1.02 & 0.91 & 1.14 \\
Counting t1 & -0.09 & 0.04 & -2.23 & $\mathbf{0 . 0 2 6}$ & 0.92 & 0.85 & 0.99 \\
Nonverbal reasoning t1 & -0.12 & 0.04 & -2.94 & $\mathbf{0 . 0 0 3}$ & 0.89 & 0.82 & 0.96 \\
Working memory t1 & -0.13 & 0.12 & -1.06 & 0.287 & 0.88 & 0.69 & 1.12 \\
Rapid naming t1 & -0.11 & 0.09 & -1.21 & 0.225 & 0.89 & 0.75 & 1.07 \\
Vocabulary t1 & 0.02 & 0.06 & 0.27 & 0.788 & 1.02 & 0.90 & 1.15 \\
\hline Model fit measures & Deviance & AIC & $R^{2} \mathrm{~N}$ & $\chi^{2}$ & $\mathrm{df}$ & $p$ & \\
\hline & 172.05 & 186.05 & 0.26 & 34.89 & 6 & $<.001$ & \\
\hline
\end{tabular}

Note. Estimates represent the log odds of MLD25 vs. TYP (reference group). MLD25 = mathematical learning difficulties (performance $\leq 25$ th percentile), TYP $=$ typically performing (performance $>25$ th percentile). $\mathrm{SNMP}=$ symbolic numerical magnitude processing, $\mathrm{OR}=$ odds ratio, $\mathrm{CI}=$ confidence interval, AIC $=$ Akaike information criterion, $R^{2} \mathrm{~N}=$ Nagelkerke's $R^{2}$. 

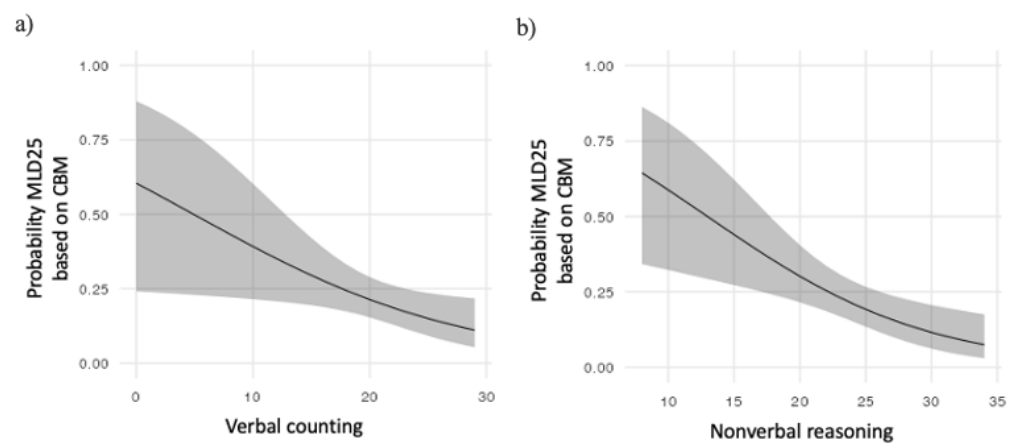

\section{Figure 2}

Predicted Probability with 95\% Confidence Interval for a Status of MLD25 in Curriculum-Based Mathematics versus a) Verbal Counting and b) Nonverbal Reasoning

\section{Predictors of MLD10 and LOW Status Arithmetic Fluency (RQ3.1)}

A multinomial logistic regression analysis was run with a dependent variable of status consisting of three status groups (TYP, LOW, MLD10). The model was statistically significant, $\chi^{2}(12)=65.01, p<.001$, and explained $28.0 \%$ of the variance in status (Table 5). When MLD10 was compared to TYP, the results were similar to the MLD25 status; SNMP, counting skills, and rapid automatized naming, predicted MLD10 status (SNMP: $B=-.22, p=.019$, odds ratio $=.81$; counting skills: $B=-.16, p=$ .008 , odds ratio $=.85$; and rapid automatized naming: $B=-.28, p=.038$, odds ratio $=$ .75). When LOW was compared to TYP, only domain-specific skills, SNMP $(B=-.17$, $p=.021$, odds ratio $=.85)$ and counting skills $(B=-.13, p=.009$, odds ratio $=.88)$ were significant predictors for LOW status. None of the predictors were significant when comparing MLD10 with LOW. Figure 3 illustrates how decreasing performance in SNMP and counting skills are associated with an increased likelihood of MLD10 and LOW status, and similarly for rapid automatized naming for MLD10 status.

\section{Curriculum-Based Mathematics (RQ3.2)}

A similar multinomial logistic regression analysis was done for CBM. The model was statistically significant, $\chi^{2}(12)=47.12, p<.001$, and explained $21 \%$ of the variance in status (Table 6). When MLD10 was compared to TYP, the same two factors that had predicted MLD25 predicted also MLD10 status: counting skills $(B=-.15, p=.006$, odds ratio $=.86)$ and nonverbal reasoning $(B=-.11, p=.046$, odds ratio $=.89)$. In addition, rapid automatized naming $(B=-.28, p=.033$, odds ratio $=.76)$ predicted MLD10 status. When LOW was compared to TYP, again, nonverbal reasoning predicted the status $(B=-.13, p=.009$, odds ratio $=.88)$, but counting skills was no longer a significant predictor. Instead, working memory predicted LOW status $(B=-$ $.33, p=.035$, odds ratio $=.72$ ). These differences were also visible when comparing MLD10 versus LOW. Decreasing working memory skills was associated with a higher probability of LOW status than MLD10, and vice versa for rapid automatized naming. Figure 4 illustrates the predicted probabilities for the status of TYP, LOW, and MLD10 versus counting skills, nonverbal reasoning, working memory and rapid automatized naming. 
Table 5

Multinomial Logistic Regression Analysis for MLD10 and LOW Status on Arithmetic Fluency

\begin{tabular}{|c|c|c|c|c|c|c|c|}
\hline \multirow[b]{2}{*}{ Predictor } & \multirow[b]{2}{*}{$B$} & \multirow[b]{2}{*}{$S E$} & \multirow[b]{2}{*}{$Z$} & \multirow[b]{2}{*}{$p$} & \multirow[b]{2}{*}{ OR } & \multicolumn{2}{|c|}{$95 \% \mathrm{CI}$ for OR } \\
\hline & & & & & & Lower & Upper \\
\hline \multicolumn{8}{|l|}{ MLD10-TYP } \\
\hline Intercept & 7.30 & 2.12 & 3.44 & $<.001$ & NA & NA & NA \\
\hline SNMP tl & -0.22 & 0.09 & -2.35 & 0.019 & 0.81 & 0.67 & 0.96 \\
\hline Counting tl & -0.16 & 0.06 & -2.65 & 0.008 & 0.85 & 0.76 & 0.96 \\
\hline Nonverbal reasoning tl & -0.01 & 0.06 & -0.16 & 0.876 & 0.99 & 0.88 & 1.11 \\
\hline Working memory tl & -0.09 & 0.19 & -0.49 & 0.622 & 0.91 & 0.63 & 1.32 \\
\hline Rapid naming tl & -0.28 & 0.14 & -2.07 & 0.038 & 0.75 & 0.58 & 0.98 \\
\hline Vocabulary t1 & 0.05 & 0.10 & 0.49 & 0.625 & 1.05 & 0.86 & 1.28 \\
\hline \multicolumn{8}{|l|}{ LOW-TYP } \\
\hline Intercept & 5.34 & 1.78 & 2.99 & 0.003 & NA & NA & NA \\
\hline SNMP tl & -0.17 & 0.07 & -2.31 & 0.021 & 0.85 & 0.74 & 0.98 \\
\hline Counting tl & -0.13 & 0.05 & -2.63 & 0.009 & 0.88 & 0.80 & 0.97 \\
\hline Nonverbal reasoning tl & 0.03 & 0.05 & 0.72 & 0.471 & 1.04 & 0.94 & 1.14 \\
\hline Working memory t1 & -0.12 & 0.15 & -0.80 & 0.421 & 0.89 & 0.66 & 1.19 \\
\hline Rapid naming tl & -0.18 & 0.11 & -1.62 & 0.105 & 0.83 & 0.66 & 1.04 \\
\hline Vocabulary tl & 0.01 & 0.08 & 0.10 & 0.923 & 1.01 & 0.86 & 1.18 \\
\hline \multicolumn{8}{|l|}{ MLD10-LOW } \\
\hline Intercept & 1.97 & 1.98 & 0.99 & 0.320 & NA & NA & NA \\
\hline SNMP tl & -0.05 & 0.10 & -0.52 & 0.604 & 0.95 & 0.79 & 1.15 \\
\hline Counting tl & -0.03 & 0.06 & -0.52 & 0.602 & 0.97 & 0.86 & 1.09 \\
\hline Nonverbal reasoning tl & -0.04 & 0.07 & -0.67 & 0.501 & 0.96 & 0.84 & 1.09 \\
\hline Working memory tl & 0.03 & 0.20 & 0.12 & 0.901 & 1.03 & 0.69 & 1.53 \\
\hline Rapid naming tl & -0.10 & 0.13 & -0.73 & 0.468 & 0.91 & 0.70 & 1.18 \\
\hline Vocabulary tl & 0.04 & 0.10 & 0.40 & 0.689 & 1.04 & 0.85 & 1.27 \\
\hline \multirow[t]{2}{*}{ Model fit measures } & Deviance & AIC & $R^{2} \mathrm{~N}$ & $x^{2}$ & df & $p$ & \\
\hline & 210.64 & 238.65 & 0.28 & 65.01 & 12 & $<.001$ & \\
\hline
\end{tabular}

Note. Estimates represent the log odds of MLD10 vs. TYP (reference group), LOW vs. TYP (reference group), and MLD10 vs. LOW (reference group). MLD10 = mathematical learning disorder (performance $\leq$ 10th percentile), TYP $=$ typically performing (performance $>25$ th percentile), LOW $=$ low-performing (performance between 11-25th percentile). SNMP $=$ symbolic numerical magnitude processing, $\mathrm{OR}=$ odds ratio, $\mathrm{CI}=$ confidence interval, $\mathrm{AIC}=$ Akaike information criterion, $R^{2} \mathrm{~N}=$ Nagelkerke's $R^{2}$.

a)

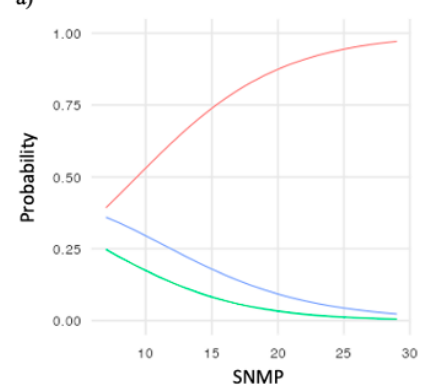

b)

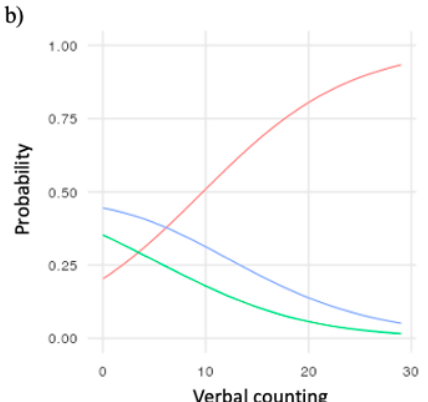

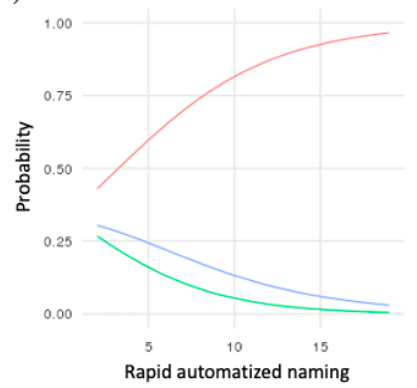

Status based on arithmetic fluency - TYP - MLD10

Figure 3

Predicted Probability for a Status of MLD10, LOW and TYP in Arithmetic Fluency versus a) Symbolic Numerical Magnitude Processing (SNMP), b) Verbal Counting, and c) Rapid Automatized Naming 
Table 6

Multinomial Logistic Regression Analysis for MLD10 and LOW Status on Curriculum-Based Mathematics

\begin{tabular}{|c|c|c|c|c|c|c|c|}
\hline \multirow[b]{2}{*}{ Predictor } & \multirow[b]{2}{*}{$B$} & \multirow[b]{2}{*}{$S E$} & \multirow[b]{2}{*}{$Z$} & \multirow[b]{2}{*}{$p$} & \multirow[b]{2}{*}{ OR } & \multicolumn{2}{|c|}{$95 \% \mathrm{CI}$ for OR } \\
\hline & & & & & & Lower & Upper \\
\hline \multicolumn{8}{|l|}{ MLD10-TYP } \\
\hline Intercept & 4.28 & 1.72 & 2.49 & 0.013 & NA & NA & NA \\
\hline SNMP tl & 0.02 & 0.08 & 0.20 & 0.840 & 1.02 & 0.87 & 1.19 \\
\hline Counting t 1 & -0.15 & 0.06 & -2.77 & 0.006 & 0.86 & 0.77 & 0.96 \\
\hline Nonverbal reasoning tl & -0.11 & 0.06 & -2.00 & 0.046 & 0.89 & 0.80 & 1.00 \\
\hline Working memory tl & 0.15 & 0.19 & 0.79 & 0.431 & 1.16 & 0.80 & 1.69 \\
\hline Rapid naming tl & -0.28 & 0.13 & -2.13 & 0.033 & 0.76 & 0.59 & 0.98 \\
\hline Vocabulary tl & 0.05 & 0.09 & 0.60 & 0.551 & 1.06 & 0.88 & 1.26 \\
\hline \multicolumn{8}{|l|}{ LOW-TYP } \\
\hline Intercept & 3.49 & 1.58 & 2.20 & 0.028 & NA & NA & NA \\
\hline SNMP tl & 0.02 & 0.07 & 0.36 & 0.719 & 1.03 & 0.90 & 1.17 \\
\hline Counting tl & -0.04 & 0.05 & -0.78 & 0.435 & 0.96 & 0.88 & 1.06 \\
\hline Nonverbal reasoning tl & -0.13 & 0.05 & -2.60 & 0.009 & 0.88 & 0.80 & 0.97 \\
\hline Working memory t1 & -0.33 & 0.15 & -2.11 & 0.035 & 0.72 & 0.53 & 0.98 \\
\hline Rapid naming $\mathrm{tl}$ & 0.03 & 0.12 & 0.25 & 0.806 & 1.03 & 0.82 & 1.29 \\
\hline Vocabulary tl & -0.02 & 0.08 & -0.23 & 0.818 & 0.98 & 0.85 & 1.14 \\
\hline \multicolumn{8}{|l|}{ MLD10-LOW } \\
\hline Intercept & 0.79 & 1.99 & 0.40 & 0.690 & NA & NA & NA \\
\hline SNMP tl & -0.01 & 0.09 & -0.09 & 0.927 & 0.99 & 0.82 & 1.19 \\
\hline Counting tl & -0.12 & 0.06 & -1.82 & 0.069 & 0.89 & 0.79 & 1.01 \\
\hline Nonverbal reasoning tl & 0.01 & 0.07 & 0.19 & 0.849 & 1.01 & 0.89 & 1.16 \\
\hline Working memory t1 & 0.48 & 0.23 & 2.09 & 0.036 & 1.61 & 1.03 & 2.52 \\
\hline Rapid naming t1 & -0.31 & 0.16 & -1.98 & 0.048 & 0.74 & 0.54 & 1.00 \\
\hline Vocabulary tl & 0.07 & 0.10 & 0.69 & 0.490 & 1.07 & 0.88 & 1.32 \\
\hline \multirow[t]{2}{*}{ Model fit measures } & Deviance & AIC & $R^{2} \mathrm{~N}$ & $x^{2}$ & df & $p$ & \\
\hline & 222.80 & 250.80 & 0.21 & 47.12 & 12 & $<.001$ & \\
\hline
\end{tabular}

Note. Estimates represent the log odds of MLD10 vs. TYP (reference group), LOW vs. TYP (reference group), and MLD10 vs. LOW (reference group). MLD10 = mathematical learning disorder (performance $\leq$ 10th percentile), TYP $=$ typically performing (performance $>25$ th percentile), $\mathrm{LOW}=$ low-performing (performance between 11-25th percentile). $\mathrm{SNMP}=$ symbolic numerical magnitude processing, $\mathrm{OR}=$ odds ratio, $\mathrm{CI}=$ confidence interval, $\mathrm{AIC}=$ Akaike information criterion, $R^{2} \mathrm{~N}=$ Nagelkerke's $R^{2}$. 


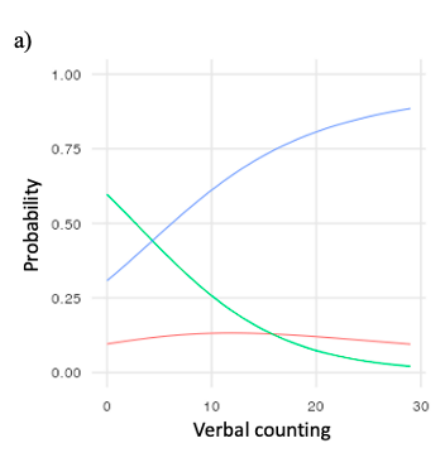

b)
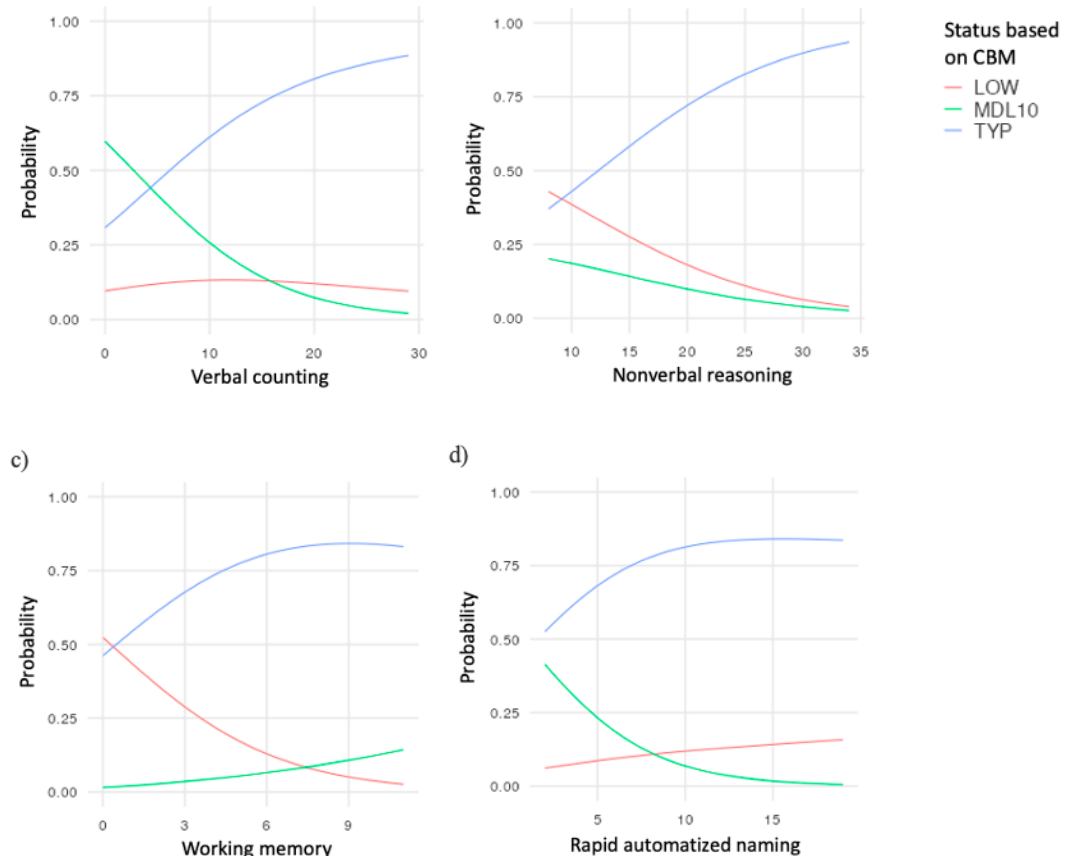

d)

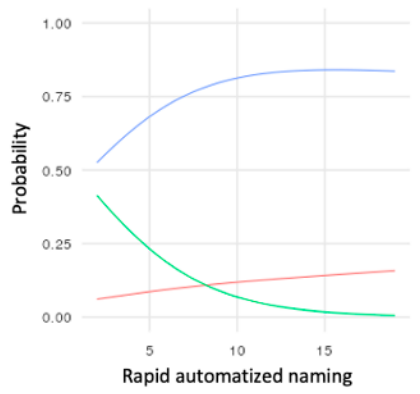

Figure 4

Predicted Probability for a Status of MLD10, LOW and TYP in Curriculum-Based Mathematics versus a) Verbal Counting b) Nonverbal Reasoning, c) Working Memory, and d) Rapid Automatized Naming

\section{Discussion}

This study investigated how domain-specific (i.e., SNMP and counting skills) and domain-general skills (i.e., nonverbal reasoning, working memory, rapid automatized naming, and vocabulary) measured in the first grade predict MLD status among third graders. Several studies have found both domain-specific (e.g., Cañizares et al., 2012; Desoete et al., 2012; Hassinger-Das et al., 2014; Landerl et al., 2004) and domaingeneral skills (e.g., David, 2012; Huijsmans et al., 2022; Mazzocco \& Grimm, 2013) to be negatively associated with MLD. However, relatively few studies have considered whether these relations are dependent on how MLD has been defined and operationalised in terms of the severity of MLD and measures of mathematics performance. The novelty of this study is that it took into consideration both the different cut-off criteria and the measures of mathematics performance (i.e., arithmetic fluency and curriculum-based mathematics) in defining the MLD status, and included several early domain-specific and domain-general skills as predictors of MLD. Our findings suggest that both different cut-off criteria and mathematics measures used for the definition of the MLD status are important to acknowledge, as these led to relatively significant variation in which students were identified as having MLD and which domain-specific and domain-general factors contributed to the MLD status.

Prior research has used various different mathematics measures for the identification of students with MLD. Typically, arithmetic fluency (Chow et al., 2021; Koponen, Aro, et al., 2018) and broader mathematics performance tests (Jordan et al., 2002) have been applied. Little is known whether these different measures identify the same participants under the same MLD status. Therefore, in our study, we first 
examined the overlap of MLD statuses (MLD25, MLD10 and LOW) based on arithmetic fluency and CBM (RQ1). For the MLD25 status, the overlap was $65 \%$, while for the MLD10 status, the share was $67 \%$, and for LOW, only $39 \%$. These results show that the use of only one type of the mathematics measure would have missed a number of children struggling with either arithmetic fluency or CBM. Consequently, using a measure reflecting one area of mathematics to define MLD may lead to an exclusion of students with difficulties in another equally relevant area of mathematics. It is thus important to consider which mathematics measures to use for the identification of MLD, and whether to rely on one or multiple measures. As we are still lacking a globally applicable diagnostic measure of MLD, we would encourage researchers to carefully report both the cut-off criteria and mathematics measures used for the identification of MLD and MLD status (e.g., LOW, MLD10) for better comparability of research findings.

Confirming that both arithmetic fluency and CBM measures are important to consider, we focused next on how domain-specific and domain-general skills predict different MLD status based on arithmetic fluency or curriculum-based mathematics.

\section{Predictors of MLD based on Arithmetic Fluency}

As hypothesized (H2.1), MLD25 status based on arithmetic fluency was predicted by SNMP, verbal counting skills and rapid automatized naming. The lower was the first-grade performance in these skills, the higher was the probability of showing weak arithmetic fluency (MLD25) in the third grade. A similar pattern of predictions was found when the MLD25 group was divided into MLD10 and LOW. As expected (H3.1), SNMP and counting skills predicted both statuses, but rapid automatized naming predicted only MLD10. That is, SNMP and counting skills predicted the status of MLD based on arithmetic fluency independent of the severity level of MLD. Weakness in early rapid automatized naming, instead, seemed to be more strongly associated with MLD10.

Prior research has shown the importance of early mathematical skills for later arithmetic and mathematics performance (Aunio \& Niemivirta, 2010; ten Braak et al., 2022), which our findings support. The role of (S)NMP in mathematics learning and MLD has been under debate due to mixed findings (Cañizares et al., 2012; De Smedt et al., 2013; De Smedt \& Gilmore, 2011; Desoete et al., 2012; Mammarella et al., 2021). Our findings give further support to SNMP being an important factor for later mathematics performance, as we found that SNMP measured at grade 1 was a significant predictor of MLD status based on arithmetic fluency at grade 3 . The task measuring SNMP involves recognition of number symbols (1-digit numbers) and understanding their related magnitude (Brankaer et al., 2017). It could be that this type of basic symbolic magnitude processing in the beginning school is relevant especially for arithmetic learning at school (De Smedt et al., 2013; Nosworthy et al., 2013), and thus a good predictor of MLD based on arithmetic fluency. Also, verbal counting skills (i.e., knowledge of number sequences) was found to predict MLD status based on arithmetic fluency. Prior research has shown that verbal counting skills are important for learning basic addition and subtraction skills, and used also as a strategy for solving unknown addition and subtraction facts (Koponen et al., 2019; Ostad, 1998). Therefore, difficulties in early verbal counting skills may slow down the learning of arithmetic facts. For these children, solving addition and subtraction facts may become more errorprone due to making mistakes in number sequences, and continuously getting incorrect 
answers between the fact and the answer may thus interrupt memorizing the facts fluently.

Rapid automatized naming was found to be the only domain-general predictor of MLD status based on arithmetic fluency, which is in line with prior research (Donker et al., 2016; Mazzocco \& Grimm, 2013). While we found non-alphanumeric rapid automatized naming to predict MLD25 and MLD10 status, Donker et al. (2016) similarly reported students with MLD25 to have weaker non-alphanumeric rapid automatized naming skills. Further, Mazzocco and Grimm (2013) found students with MLD10 to have persistent weakness in rapid automatized naming of colors compared to their peers, and also students with LOW status to show slight delay in their development of rapid naming of colors. As to why rapid automatized naming and arithmetic fact retrieval are related, in both tasks children need to access quickly and retrieve phonological representations from long-term memory (e.g., "blue" and "seven"). The role of early non-alphanumeric rapid automatized naming skills in later MLD based on arithmetic fluency seems to be important to acknowledge.

Based on our findings, both weak SNMP and counting skills could be considered as risk factors for later difficulties in arithmetic fluency, independent of the level of severity, while rapid automatized naming seems to be specifically associated with MLD10 students' arithmetic fluency. As a practical implication for early schooling, SNMP and verbal counting skills should be regularly screened in classrooms (see e.g., Brankaer et al., 2017; Nosworthy et al., 2013; Salminen \& Koponen, 2011). Those who struggle in comparing 1-digit numbers or in reciting number sequences forwards and backwards, should be provided with relevant intensified pedagogical support (i.e., intervention) as early as possible (see e.g., Ramani et al., 2017). Even if the role of early rapid automatized naming skills in MLD is important to acknowledge, training of domain-general skills, with many examples from working memory training research, has shown rather weak far transfer effects on mathematics performance (Melby-Lervåg $\&$ Hulme, 2013). However, recently Pecini et al. (2019) showed the training of rapid automatized naming using specific software to be effective in ameliorating reading accuracy and speed. Until we have solid evidence of the effectiveness of training rapid automatized naming and its transfer on improved mathematical skills, it might be more useful to focus on training mathematical skills as a preventive step with children identified with weakness in early rapid automatized naming skills.

\section{Predictors of MLD based on Curriculum-Based Mathematics}

Our findings on the predictions of MLD based on CBM differed from those of MLD based on arithmetic fluency. Here, the domain-general skills seemed to be better predictors than domain-specific skills, especially in relation to MLD10 and LOW status. Because the tasks in CBM had more variety and complexity in their mathematics content and procedures, we expected counting skills (Hassinger-Das et al., 2014), nonverbal reasoning (Engle, 2018; Huijsmans et al., 2022), working memory (David, 2012), and vocabulary (Chow et al., 2021) to predict MLD25 status. In accordance with our hypothesis (H2.2), counting skills and nonverbal reasoning, but not working memory, were found to predict MLD25 status based on CBM. When MLD25 was divided into two, counting skills only predicted the MLD10 status, but not LOW, as we would have expected (H2.3). In fact, no domain-specific skills predicted LOW status based on CBM. Regarding domain-general skills, in contrast to our hypothesis, nonverbal reasoning and rapid automatized naming, but not working memory, predicted 
MLD10 status based on CBM. Instead, working memory together with nonverbal reasoning predicted LOW status.

As elaborated above, early counting skills have shown to be associated with later mathematics performance (ten Braak et al., 2022). Concerning MLD status, our results revealed that verbal counting skills predicted especially MLD10 status based on CBM. Taken together, these findings imply that verbal counting skills are good at predicting MLD10 status independent of the mathematics measure used for identification. This further puts emphasis on supporting children's early counting skills in early schooling as a preventive step for later severe MLD.

Nonverbal reasoning was found to predict MLD status based on CBM, independent of the severity level. CBM test measured a broad range of mathematical subskills with different types of tasks (e.g., "Lisa's little finger is $4 \mathrm{~g} / \mathrm{kg} / \mathrm{cm} / \mathrm{m}$ long"; "One apple costs 3 krones, 4 apples cost _ krones.", simple word problems for fractions, and addition and subtraction algorithms). Solving these tasks thus required making logical decisions and proceeding systematically in the task (i.e., nonverbal reasoning) (Engle, 2018), which differs from solving simple arithmetic facts. This result also resonates well with Hujsmans' et al. (2022) findings showing students with MLD to perform weaker in nonverbal reasoning compared to their peers without MLD.

MLD10 and LOW based on CBM were separated by the domain-general predictors of rapid automatized naming and working memory (i.e., central executive functioning). Overall, rapid automatized naming turned out to be an important predictor of MLD10 status, as it predicted the status based on both arithmetic fluency and CBM. Previously, rapid automatized naming has been found to be related to broader mathematics performance as well, although not as strongly as to arithmetic fluency (Koponen et al., 2017). Because the tasks in mathematics performance tests typically involve more processes than quick retrieval only, the relationship of rapid automatized naming with broader mathematics performance are weaker than with arithmetic fluency. This was also evident in our study ( $r=.43$ with arithmetic fluency, and $r=.33$ with CBM).

Interestingly, working memory, and more specifically, central executive, predicted only LOW status based on CBM, although prior research has found its role to be significant in mathematics learning (Friso-van den Bos et al., 2013) and MLD. Students with MLD often have a working memory deficit (Andersson \& Lyxell, 2007; David, 2012; Passolunghi \& Mammarella, 2010). Concerning the MLD status here, our results partly reflect the findings by Huijsman et al. (2022), who found students identified as LOW to be weaker than MLD10 in the visual component of working memory. Even if we used a generally recognized backwards digit span as a measure of central executive in our study, it might be that the central executive measured this way captured only part of the construct, and a broader measure would have been needed to retain its predictive power and thus obtain a similar effect on MLD as in previous studies.

\section{Limitations and Future Directions}

The current study has some limitations that need to be noted. First, although we included many domain-specific and domain-general skills based on prior research, we may have missed some other important factors as predictors, such as non-symbolic numerical magnitude processing, subitizing, or object counting as domain-specific skills, or inclusion of other components of working memory (i.e., phonological loop and visuo-spatial working memory) and language (e.g., receptive vocabulary or syntax). Their role as a predictor of MLD would be of future interest to explore. 
Concerning the severity criteria for the MLD status, we based our grouping of children on sample-based percentiles both in arithmetic fluency and CBM. It might be argued that it would have been better to use mathematics tests with norms for identifying students with MLD. At the time of the study, neither standardized broad mathematics performance tests nor combined tests of addition and subtraction facts were available for this age group in Norway. Therefore, we developed a new CBM test, and applied sample-based percentiles in both CBM and arithmetic fluency (i.e., a combination of addition and subtraction fluency subtests) for the identification of MLD. The lack of global standardized mathematics measures to be used in MLD studies is problematic in terms of the comparability of results, and should be addressed in future research on MLD.

Note, that because of practical reasons, our sample was restricted to only include children from the Oslo region in Norway, due to which caution should be exercised in generalizing the findings to other contexts. Also, the Covid-19 pandemic complicated the final stages of the data collection due to which one school withdrew from the study and the data collection in spring 2021 needed to be organized online. However, there are no indications of this causing any bias in our data.

\section{Conclusions}

Our findings suggest that both the different cut-off criteria and mathematics measures used for defining and operationalizing the MLD status are important to acknowledge in studies, as these may lead to relatively significant variation in which students are identified as having MLD and which factors contribute to the MLD status. In relative terms, domain-specific skills appear to be more predictive when the MLD status is based on arithmetic fluency, while domain-general skills seem more influential when the MLD status is based on CBM. Counting skills and rapid automatized naming, instead, appear to be robust predictors of MLD status regardless of the mathematics measure used. As a practical implication for the prevention of MLD, we advocate focusing on screening children's SNMP and verbal counting skills in early grades, and providing appropriate intervention in these for those in need of educational support.

\section{References}

Andersson, U., \& Lyxell, B. (2007). Working memory deficit in children with mathematical difficulties: A general or specific deficit? Journal of Experimental Child Psychology, 96(3), 197-228. https://doi.org/10.1016/j.jecp.2006.10.001

Aunio, P., Korhonen, J., Ragpot, L., Törmänen, M., \& Henning, E. (2021). An early numeracy intervention for first-graders at risk for mathematical learning difficulties. Early Childhood Research Quarterly, 55, 252-262. https://doi.org/10.1016/j.ecresq.2020.12.002

Aunio, P., Korhonen, J., Ragpot, L., Törmänen, M., Mononen, R., \& Henning, E. (2019). Multi-factorial approach to early numeracy - The effects of cognitive skills, language factors and kindergarten attendance on early numeracy performance of South African first graders. International Journal of Educational Research, 97, 65-76. https://doi.org/10.1016/j.ijer.2019.06.011

Aunio, P., \& Niemivirta, M. (2010). Predicting children's mathematical performance in grade one by early numeracy. Learning and Individual Differences, 20(5), 427435. https://doi.org/10.1016/j.lindif.2010.06.003

Baddeley, A. D., \& Logie, R. H. (1999). Working memory: The multiple-component model. In Models of working memory: Mechanisms of active maintenance and 
executive control (pp. 28-61). Cambridge University Press. https://doi.org/10.1017/CBO9781139174909.005

Brankaer, C., Ghesquière, P., \& De Smedt, B. (2017). Symbolic magnitude processing in elementary school children: A group administered paper-and-pencil measure (SYMP Test). Behavior Research Methods, 49(4), 1361-1373. https://doi.org/10.3758/s13428-016-0792-3

Butterworth, B. (2005). Developmental Dyscalculia. In Handbook of Mathematical Cognition (pp. 455-467). Psychology Press.

Cañizares, D. C., Crespo, V. R., \& Alemañy, E. G. (2012). Symbolic and non-symbolic number magnitude processing in children with developmental dyscalculia. The Spanish Journal of Psychology, 15(3), 952-966. https://doi.org/10.1016/j.jecp.2008.12.006

Chow, J. C., \& Ekholm, E. (2019). Language domains differentially predict mathematics performance in young children. Early Childhood Research Quarterly, 46, 179-186. https://doi.org/10.1016/j.ecresq.2018.02.011

Chow, J. C., Majeika, C. E., \& Sheaffer, A. W. (2021). Language skills of children with and without mathematics difficulty. Journal of Speech, Language, and Hearing Research, 64(9), 3571-3577. https://doi.org/10.1044/2021_JSLHR-20-00378

Chu, F. W., vanMarle, K., \& Geary, D. C. (2016). Predicting children's reading and mathematics achievement from early quantitative knowledge and domaingeneral cognitive abilities. Frontiers in Psychology, 7, 775. https://doi.org/10.3389/fpsyg.2016.00775

Cross, A. M., Joanisse, M. F., \& Archibald, L. M. D. (2019). Mathematical abilities in children with developmental language disorder. Language, Speech, and Hearing Services in Schools, 50(1), 150-163. https://doi.org/10.1044/2018_LSHSS-180041

David, C. V. (2012). Working memory deficits in Math learning difficulties: A metaanalysis. International Journal of Developmental Disabilities, 58(2), 67-84. https://doi.org/10.1179/2047387711Y.0000000007

De Smedt, B., \& Gilmore, C. K. (2011). Defective number module or impaired access? Numerical magnitude processing in first graders with mathematical difficulties. Journal of Experimental Child Psychology, 108(2), 278-292. https://doi.org/10.1016/j.jecp.2010.09.003

De Smedt, B., Noël, M.-P., Gilmore, C., \& Ansari, D. (2013). How do symbolic and non-symbolic numerical magnitude processing skills relate to individual differences in children's mathematical skills? A review of evidence from brain and behavior. Trends in Neuroscience and Education, 2(2), 48-55. https://doi.org/10.1016/j.tine.2013.06.001

Dehaene, S., Dehaene-Lambertz, G., \& Cohen, L. (1998). Abstract representations of numbers in the animal and human brain. Trends in Neurosciences, 21(8), 355361. https://doi.org/10.1016/S0166-2236(98)01263-6

Desoete, A., Ceulemans, A., Weerdt, F. D., \& Pieters, S. (2012). Can we predict mathematical learning disabilities from symbolic and non-symbolic comparison tasks in kindergarten? Findings from a longitudinal study. British Journal of Educational Psychology, 82(1), 64-81. https://doi.org/10.1348/20448279.002002

Donker, M., Kroesbergen, E., Slot, E., Van Viersen, S., \& De Bree, E. (2016). Alphanumeric and non-alphanumeric Rapid Automatized Naming in children 
with reading and/or spelling difficulties and mathematical difficulties. Learning and Individual Differences, 47, 80-87. https://doi.org/10.1016/j.lindif.2015.12.011

Engle, R. W. (2018). Working memory and executive attention: A revisit. Perspectives on Psychological Science, 13(2), 190-193. https://doi.org/10.1177/1745691617720478

Friso-van den Bos, I., van der Ven, S. H. G., Kroesbergen, E. H., \& van Luit, J. E. H. (2013). Working memory and mathematics in primary school children: A metaanalysis. Educational Research Review, 10, 29-44. https://doi.org/10.1016/j.edurev.2013.05.003

Geary, D. C. (2011). Consequences, characteristics, and causes of mathematical learning disabilities and persistent low achievement in mathematics. Journal of Developmental and Behavioral Pediatrics: JDBP, 32(3), 250-263. https://doi.org/10.1097/DBP.0b013e318209edef

Geary, D. C., Hoard, M. K., Nugent, L., \& Bailey, D. H. (2012). Mathematical cognition deficits in children with learning disabilities and persistent low achievement: A five-year prospective study. Journal of Educational Psychology, 104(1), 206-223. https://doi.org/10.1037/a0025398

Gersten, R., Jordan, N. C., \& Flojo, J. R. (2005). Early identification and interventions for students with mathematics difficulties. Journal of Learning Disabilities, 38(4), 293-304. https://doi.org/10.1177/00222194050380040301

Hassinger-Das, B., Jordan, N. C., Glutting, J., Irwin, C., \& Dyson, N. (2014). Domaingeneral mediators of the relation between kindergarten number sense and firstgrade mathematics achievement. Journal of Experimental Child Psychology, 118, 78-92. https://doi.org/10.1016/j.jecp.2013.09.008

Huijsmans, M. D. E., Kleemans, T., \& Kroesbergen, E. H. (2022). The cognitive profiles for different samples of mathematical learning difficulties and their similarity to typical development: Evidence from a longitudinal study. Journal of Experimental Child Psychology, 214, 105288. https://doi.org/10.1016/j.jecp.2021.105288

Jordan, N. C., Kaplan, D., \& Hanich, L. B. (2002). Achievement growth in children with learning difficulties in mathematics: Findings of a two-year longitudinal study. Journal of Educational Psychology, 94(3), 586-597. https://doi.org/10.1037/0022-0663.94.3.586

Jordan, N. C., Kaplan, D., Ramineni, C., \& Locuniak, M. N. (2009). Early math matters: Kindergarten number competence and later mathematics outcomes. Developmental Psychology, 45(3), 850-867. https://doi.org/10.1037/a0014939

Klausen, T., \& Reikerås, E. (2016). Regnefaktaprøven. Lesesenteret, University of Stavanger, Norway.

Koponen, T., Aro, M., Poikkeus, A.-M., Niemi, P., Lerkkanen, M.-K., Ahonen, T., \& Nurmi, J.-E. (2018). Comorbid fluency difficulties in reading and math: Longitudinal stability across early grades. Exceptional Children, 84(3), 298311. https://doi.org/10.1177/0014402918756269

Koponen, T., Aunola, K., \& Nurmi, J.-E. (2019). Verbal counting skill predicts later math performance and difficulties in middle school. Contemporary Educational Psychology, 59, 101803. https://doi.org/10.1016/j.cedpsych.2019.101803

Koponen, T., Eklund, K., \& Salmi, P. (2018). Cognitive predictors of counting skills. Journal of Numerical Cognition, 4(2), 410-428. 
https://doi.org/10.5964/jnc.v4i2.116

Koponen, T., Georgiou, G., Salmi, P., Leskinen, M., \& Aro, M. (2017). A meta-analysis of the relation between RAN and mathematics. Journal of Educational Psychology, 109(7), 977-992. https://doi.org/10.1037/edu0000182

Kroesbergen, E. H., \& van Dijk, M. (2015). Working memory and number sense as predictors of mathematical (dis-)ability. Zeitschrift Für Psychologie, 223(2), 102-109. https://doi.org/10.1027/2151-2604/a000208

Kyttälä, M., \& Lehto, J. E. (2008). Some factors underlying mathematical performance: The role of visuospatial working memory and non-verbal intelligence. European Journal of Psychology of Education, 23(1), 77. https://doi.org/10.1007/BF03173141

Landerl, K., Bevan, A., \& Butterworth, B. (2004). Developmental dyscalculia and basic numerical capacities: A study of 8-9-year-old students. Cognition, 93(2), 99125. https://doi.org/10.1016/j.cognition.2003.11.004

LeFevre, J.-A., Fast, L., Skwarchuk, S.-L., Smith-Chant, B. L., Bisanz, J., Kamawar, D., \& Penner-Wilger, M. (2010). Pathways to mathematics: Longitudinal predictors of performance. Child Development, 81(6), 1753-1767. https://doi.org/10.1111/j.1467-8624.2010.01508.x

Lin, X., Peng, P., \& Luo, H. (2021). The deficit profile of elementary students with computational difficulties versus word problem-solving difficulties. Learning Disability Quarterly, 44(2), 110-122. https://doi.org/10.1177/0731948719865499

Lopez-Pedersen, A., Mononen, R., Korhonen, J., Aunio, P., \& Melby-Lervåg, M. (2021). Validation of an early numeracy screener for first graders. Scandinavian Journal of Educational Research, 65(3), 404-424. https://doi.org/10.1080/00313831.2019.1705901

Mammarella, I. C., Toffalini, E., Caviola, S., Colling, L., \& Szücs, D. (2021). No evidence for a core deficit in developmental dyscalculia or mathematical learning disabilities. Journal of Child Psychology and Psychiatry, 62(6), 704714. https://doi.org/10.1111/jcpp.13397

Mazzocco, M. M. M., Feigenson, L., \& Halberda, J. (2011). Impaired acuity of the approximate number system underlies mathematical learning disability (dyscalculia). Child Development, 82(4), 1224-1237. https://doi.org/10.1111/j.1467-8624.2011.01608.x

Mazzocco, M. M. M., \& Grimm, K. J. (2013). Growth in Rapid Automatized Naming from Grades $\mathrm{K}$ to 8 in children with math or reading disabilities. Journal of Learning Disabilities, 46(6), 517-533. https://doi.org/10.1177/0022219413477475

Mazzocco, M. M. M., Myers, G. F., Lewis, K. E., Hanich, L. B., \& Murphy, M. M. (2013). Limited knowledge of fraction representations differentiates middle school students with mathematics learning disability (dyscalculia) versus low mathematics achievement. Journal of Experimental Child Psychology, 115(2), 371-387. https://doi.org/10.1016/j.jecp.2013.01.005

Melby-Lervåg, M., \& Hulme, C. (2013). Is working memory training effective? A metaanalytic review. Developmental Psychology, 49(2), 270-291. https://doi.org/10.1037/a0028228

Menon, V. (2016). Working memory in children's math learning and its disruption in dyscalculia. Current Opinion in Behavioral Sciences, 10, 125-132. 
https://doi.org/10.1016/j.cobeha.2016.05.014

Mussolin, C., Mejias, S., \& Noël, M.-P. (2010). Symbolic and nonsymbolic number comparison in children with and without dyscalculia. Cognition, 115(1), 10-25. https://doi.org/10.1016/j.cognition.2009.10.006

Nosworthy, N., Bugden, S., Archibald, L., Evans, B., \& Ansari, D. (2013). A twominute paper-and-pencil test of symbolic and nonsymbolic numerical magnitude processing explains variability in primary school children's arithmetic competence. PLOS ONE, 8(7), e67918. https://doi.org/10.1371/journal.pone.0067918

Ostad, S. A. (1998). Developmental differences in solving simple arithmetic word problems and simple number-fact problems: A comparison of mathematically normal and mathematically disabled children. Mathematical Cognition, 4(1), 119. https://doi.org/10.1080/135467998387389

Passolunghi, M. C., \& Mammarella, I. C. (2010). Spatial and visual working memory ability in children with difficulties in arithmetic word problem solving. European Journal of Cognitive Psychology, 22(6), 944-963. https://doi.org/10.1080/09541440903091127

Pecini, C., Spoglianti, S., Bonetti, S., Di Lieto, M. C., Guaran, F., Martinelli, A., Gasperini, F., Cristofani, P., Casalini, C., Mazzotti, S., Salvadorini, R., Bargagna, S., Palladino, P., Cismondo, D., Verga, A., Zorzi, C., Brizzolara, D., Vio, C., \& Chilosi, A. M. (2019). Training RAN or reading? A telerehabilitation study on developmental dyslexia. Dyslexia, 25(3), 318-331. https://doi.org/10.1002/dys.1619

Pina, V., Fuentes, L. J., Castillo, A., \& Diamantopoulou, S. (2014). Disentangling the effects of working memory, language, parental education, and non-verbal intelligence on children's mathematical abilities. Frontiers in Psychology, 5, 415. https://doi.org/10.3389/fpsyg.2014.00415

Price, G., \& Ansari, D. (2013). Dyscalculia: Characteristics, causes, and treatments. Numeracy, 6(1). http://dx.doi.org/10.5038/1936-4660.6.1.2

Purpura, D. J., Day, E., Napoli, A. R., \& Hart, S. A. (2017). Identifying domain-general and domain-specific predictors of low mathematics performance: A Classification and regression tree analysis. Journal of Numerical Cognition, 3(2), 365-399. https://doi.org/10.5964/jnc.v3i2.53

Purpura, D. J., \& Ganley, C. M. (2014). Working memory and language: Skill-specific or domain-general relations to mathematics? Journal of Experimental Child Psychology, 122, 104-121. https://doi.org/10.1016/j.jecp.2013.12.009

Ramani, G. B., Jaeggi, S. M., Daubert, E. N., \& Buschkuehl, M. (2017). Domainspecific and domain-general training to improve kindergarten children's mathematics. Journal of Numerical Cognition, 3(2), 468-495. https://doi.org/10.5964/jnc.v3i2.31

Raven, J. C., Court, J. H., \& Raven, J. (1990). Manual for Raven's progressive matrices and vocabulary scales: Section 2, Coloured progressive matrices. Oxford University Press.

Rousselle, L., \& Noël, M.-P. (2007). Basic numerical skills in children with mathematics learning disabilities: A comparison of symbolic vs non-symbolic number magnitude processing. Cognition, 102(3), 361-395. https://doi.org/10.1016/j.cognition.2006.01.005

Salihu, L., \& Räsänen, P. (2018). Mathematics skills of Kosovar primary school 
children: A special view on children with mathematical learning difficulties. International Electronic Journal of Elementary Education, 10(4), 421-430. Retrieved from https://iejee.com/index.php/IEJEE/article/view/409

Salminen, J., \& Koponen, T. (2011). Oppimisen arviointi: Matematiikan oppimisen seurannan välineet. Käsikirja [LukiMat-Assessment of learning: Progress monitoring of mathematics learning. Manual]. Niilo Mäki Institute.

Semel, E., Wiig, E., \& Secord, W. (2003). Clinical Evaluation of Language Fundamentals - Fourth Edition (CELF-4). Norwegian version. Pearson.

Stock, P., Desoete, A., \& Roeyers, H. (2010). Detecting children with arithmetic disabilities from kindergarten: Evidence from a 3-year longitudinal study on the role of preparatory arithmetic abilities. Journal of Learning Disabilities, 43(3), 250-268. https://doi.org/10.1177/0022219409345011

ten Braak, D., Lenes, R., Purpura, D. J., Schmitt, S. A., \& Størksen, I. (2022). Why do early mathematics skills predict later mathematics and reading achievement?

The role of executive function. Journal of Experimental Child Psychology, 214, 105306. https://doi.org/10.1016/j.jecp.2021.105306

The jamovi project. (2021). Jamovi (2.0) [Computer software]. https://www.jamovi.org

Tolar, T. D., Fuchs, L., Fletcher, J. M., Fuchs, D., \& Hamlett, C. L. (2016). Cognitive profiles of mathematical problem solving learning disability for different definitions of disability. Journal of Learning Disabilities, 49(3), 240-256. https://doi.org/10.1177/0022219414538520

Toll, S. W. M., \& Van Luit, J. E. H. (2014). Explaining numeracy development in weak performing kindergartners. Journal of Experimental Child Psychology, 124, 97111. https://doi.org/10.1016/j.jecp.2014.02.001

Van Luit, J. E. H., \& Toll, S. W. M. (2018). Associative cognitive factors of math problems in students diagnosed with developmental dyscalculia. Frontiers in Psychology, 9, 1907. https://doi.org/10.3389/fpsyg.2018.01907

Wechsler, D. (2017). WISC-V Wechsler intelligence Scale for Children-fifth edition. Norwegian version.

Willburger, E., Fussenegger, B., Moll, K., Wood, G., \& Landerl, K. (2008). Naming speed in dyslexia and dyscalculia. Learning and Individual Differences, 18(2), 224-236. https://doi.org/10.1016/j.lindif.2008.01.003

World Health Organization. (2019). International Statistical Classification of Diseases and Related Health Problems (11th ed.). https://icd.who.int/en

Zhang, X., Räsänen, P., Koponen, T., Aunola, K., Lerkkanen, M.-K., \& Nurmi, J.-E. (2020). Early cognitive precursors of children's mathematics learning disability and persistent low achievement: A 5-year longitudinal study. Child Development, 91(1), 7-27. https://doi.org/10.1111/cdev.13123 